\title{
Serum Apoprotein (ApoA1 and ApoB) in Myocardial infarction
}

\author{
KA JHUMA ${ }^{\mathrm{a}}$, MM HOQUE ${ }^{\mathrm{b}}$
}

\begin{abstract}
Summary:
30 diagnosed cases (Male26, Female 4) of MI (myocardial infarction) with the mean age of $55.5 \pm 9.8$ years (range 40 70 years) were included in a case control study to evaluate their apoprotein status. Serum apoA1 and apoB were measured and compared with those of age and sex matched healthy control subjects. Mean serum apoA1 concentration found significantly low in MI cases ( $91.84 \pm 11.2 \mathrm{mg} / \mathrm{dl}$ ) compared to control (123.2 \pm 10.5 $\mathrm{mg} / \mathrm{dl}$ ) and that of apoB found significantly high in MI cases( $135.3 \pm 23.0 \mathrm{mg} / \mathrm{dl})$ compared to control (66.2 \pm 10.0 $\mathrm{mg} / \mathrm{dl})$.Serum apoB/apoA1 ratio of MI cases (1.49 \pm 0.3$)$
\end{abstract}

\section{Introduction}

Coronary artery disease (CAD) is one of the leading causes of death from global point of view. The identification of subjects at risk of developing CAD is an important public health issue ${ }^{1}$. Atherosclerosis is the underlying cause in more than half of the patients with $\mathrm{CAD}^{2}$. Dyslipidemia is the corner stone of atherosclerotic process. Commonly serum total cholesterol ( TC), triacylglycerol (TAG), High density lipoprotein cholesterol (HDL-C),Low density lipoprotein cholesterol (LDL-c) are used for identification of person at risk of CAD. However serum TC can not discriminate well between individuals developing CAD and those who does not; since the TC as a whole without its functional breakup to atherogenic and antiatherogenic potential is a poor indicator of the atherosclerotic scenario $^{3}$. Traditionally serum LDL-C and HDL-C are regarded as the marker of atherogenic and antiatherogenic measure respectively, but it is not infrequent for an individual to develop CAD with traditional lipid

a. Dr. Khadija Akther Jhuma, Assistant Professor of Biochemistry, Medical College for Women \& Hospital, Plot4, Road-9, Sector-1, Uttara Model Town, Dhaka-1230.

b. Prof. MM Hoque, Professor of Biochemistry, Bangabandhu Shiekh Mujib Medical University, Shahbag, Dhaka.

Address of Correspondence: Prof. MM Hoque, Professor of Biochemistry, Bangabandhu Shiekh Mujib Medical University, Shahbag, Dhaka.

Received: 19 August, 2007

Accepted: 6 April, 2008 also found significantly higher than that of control (0.54 \pm 0.1$)$.Since the serum apoA1 and apoB concentration stand for relatively more comprehensive measure of antiatherogenic and atherogenic potential respectively rather than the traditional lipid profile; measurement of this apoprotein and their ratio may be more robust and specific marker for identification of individuals at risk of MI even in individuals with normal traditional lipid profile.

Key word: ApoA1, ApoB, MI

(J Bangladesh Coll Phys Surg 2008; 26: 62-66)

profile well within desired level, because LDL-C and HDL-C are not the complete representation of atherogenic and antiatherogenic lipoprotein .Important atherogenic lipoprotein are chylomicron (CM), chylomicron ramnant (CMR), very low density lipoprotein(VLDL), intermediate density lipoprotein (IDL), low density lipoprotein (LDL), and lipoprotein(a) $[\mathrm{LP}(\mathrm{a})]$; all of which contain apoB. Although HDL is treated as antiatherogenic but the different subtypes of HDL have different degree of antiatherogenic potential; some subtype believed to be rather atherogenic and all subtypes do not containing apoA1.It is claimed that HDL contain apoA1 are antiatherogenic since apoA1 stimulate LCAT and thus help in reverse cholesterol transport (RCT) by facilitating HDL maturation. HDL containing apo- $\mathrm{A}_{\text {II }}$ counter act the RCT since apo- $\mathrm{A}_{\text {II }}$ inhibit the LCAT. So the antiatherogenecity of $\mathrm{HDL}_{1}$ which has no apoA1 (contain only apoE) and that of other HDL subtypes with apo $A_{\text {II }}$ is doubtful. So HDL-C cannot represent complete antiatherogenic potential of $\mathrm{HDL}^{4}$.

With this perspective recently the major apolipoproteins like apoA1 and apoB have received attention and addressed as the major determinant of the metabolic fate of different lipoprotein ${ }^{5}$. The CAD has been found to be positively correlated with apolipoprotein $\mathrm{B}$ and inversely correlated with apolipoprotein $\mathrm{A}_{1}{ }^{6}$.

ApoA1 stimulate the reverse cholesterol transport (RCT), decrease the extent of lipid deposition and also inhibit the infiltrating monocyte/macrophages in 
aortic intima which initiate the initial stage of fatty streak formation ${ }^{7}$. Reduced plasma level of ApoA1 was found in AMI patient ${ }^{8}$. ApoA1 level can be used to predict future $\mathrm{CAD}$ among the young and in adult not yet manifestating the disease ${ }^{9}$. Although HDL considered to be rather antiatherogenic but some HDL subtype (e.g. HDL1) have recently being identified to be atherogenic and they contain no ApoA $1^{10}$. So the individuals with normal or even raised HDL-C may be found to have CAD due probably to the predominance of HDL1 subtype or the HDL subtypes without apoA1. Therefore ApoA1 rather than HDL-C seems to be more reliable assessor of antiatherogenic potential.

Increased level of plasma apoB was shown to be a risk factor for atherosclerosis ${ }^{2}$. Apo B moiety of LDL seems particularly important for its atherogenicity, because lipoproteins without apo-B apparently do not produce atherosclerosis ${ }^{11}$. LDL are heterogenous in size and density and composed of fifteen different subtypes. Smaller and denser LDL subtypes (eg .LDL $4,5,6$ etc ) are lipid depleted particles (less cholesterol containing) but more atherogenic than larger LDL subtypes (eg LDL 1,2,3 etc) which are relatively lipid rich but all LDL subtypes plus other apo-B containing atherogenic lipoproteins contain identical $\&$ equal apo-B content irrespective of their varied cholesterol content. CAD patients are likely to have more smaller and denser LDL particle. Therefore LDL-C is an inadequate measure of LDL atherogenicity ${ }^{12,13,14}$. Measuring $A p o B$ provides a direct estimate of the total number of LDL particles irrespective of their sub types 15 . So only the LDL-C measurement is a poor reflections of atherogenicity; rather ApoB stands for the complete and comprehensive picture of atherogenic risk. Because apo-B accounts all known atherogenic LP (in addition to LDL) and also the number of various LDL subtypes.

The CAD patient had significantly lower ApoA1 but higher ApoB. Both ApoA1 and B had significant discriminative power between $\mathrm{CAD}$ patients and normal individuals. So measurement of serum apoA1 $\&$ apoB appears to be more judicious clinically.

\section{Materials and Methods}

This case control study was carried out from july 2003 to June 2004 in the Department of
Biochemistry, Dhaka Medical College, Dhaka in cooperation with the immunology Dept, BIRDEM, Dhaka. Ethical clearance was taken from Ethical committee of Dhaka Medical College. A total 50 non smoker, non-alcholic subjects free from DM, renal disease, thyroid disease, liver disease and having no history of taking antihypertensive or antihyperlipidemic drugs were studied. Fasting blood glucose, serum creatinine, TSH, serum bilirubin \& ALT were measured in all study subjects to exclude DM, renal diseases, thyroid \& liver diseases. Among the study subject 30 were the diagnosed MI cases collected from Cardiology ward in Dhaka Medical College and 20 were age and sex matched healthy control selected from colleagues \& relatives. All study subjects were included after taking their informed written consent .MI diagnosis based on characteristic chest pain, ECG finding and rise and fall of serum cardiac marker.

$5 \mathrm{ml}$ fasting venous blood was collected from each subject with all aseptic precautions and allowed to clot at room temperature \& centrifuged for 10-15 minutes at $2500 \mathrm{rpm}$. The separated serum was stored frozen at $-35^{0} \mathrm{c}$ until used for the measurement of apoprotein (apoA1 and apoB).

Laboratory Method Serum apoA1 \& ApoB concentration was estimated by immunonephelometric methed with commercially available kits using BN system of Dade Behring Marburg GmbH, USA 16,17. Results were express as their mean \pm SD (Standard deviation)

Statistical Analysis: The result were analysed in SPSS by using unpaired student $\mathrm{t}$-test, $\mathrm{P}<0.05$ were taken as a level of significance.

\section{Results}

Study subjects were grouped as Group -I (30 MI cases,) and Group-II (20 normal control). Group-I included 26 males $(86.6 \%)$ and 4 female $(13.3 \%)$ of age range $40-70$ years. In Group-II , 16 male (80\%) and 4 female $(20 \%)$ normal control were selected with age range 40-70 years. (Table -I) .

Table-II shows the serum apoA1 \& apoB concentration in different Groups. In Group-I (case) mean apoA1 concentration found $91.84 \pm 11.2 \mathrm{mg} / \mathrm{dl}$ 
with the range 68.0- 105.0 and that of apo B concentration found $135.3 \pm 23.0 \mathrm{mg} / \mathrm{dl}$ with the range 106.0-187.0. In Group-II (Normal control) mean apoA1 concentration was $123.2 \pm 10.5 \mathrm{mg} / \mathrm{dl}$ with the range 105.0 - 145.0 and of apoB concentration was $66.2 \pm 10.0 \mathrm{mg} / \mathrm{dl}$ with the range 55.0-94.9 respectively. In MI cases apoB found significantly increased and apoA1 found significantly decreased compared to control.

Table III shows the comparison of ratio of apoB/apoA1. The ratio in group1 (cases) and group II (normal control) were $1.49 \pm 0.30$ and $0.54 \pm 0.10$ respectively, which was found significantly elevated in case compared to normal control.

\section{Table1}

Age \& sex distribution of study subjects

\begin{tabular}{|c|c|c|c|c|}
\hline \multicolumn{5}{|c|}{ Age \& sex distribution of study subjects } \\
\hline \multirow[t]{2}{*}{ Study Subject } & \multicolumn{2}{|c|}{ Age (year) } & \multicolumn{2}{|c|}{ Sex } \\
\hline & Mean $\pm \mathrm{SD}$ & Age range & Male & Female \\
\hline $\begin{array}{l}\text { MI cases }(\mathrm{Gr}-\mathrm{I}) \\
(\mathrm{n}=30)\end{array}$ & $55.5 \pm 9.8$ & $40-70$ & 26 & 4 \\
\hline $\begin{array}{l}\text { Normal Control(Gr-II) } \\
(\mathrm{n}=20)\end{array}$ & $52.6 \pm 9.6$ & $40-70$ & 16 & 4 \\
\hline
\end{tabular}

Table II

Serum A1 and Apo B concentration of the study subjects

\begin{tabular}{lccc}
$\begin{array}{l}\text { Parameter } \\
\text { Mean } \pm \text { SD }\end{array}$ & $\begin{array}{c}\text { Group I (cases) } \\
\mathrm{n}=30\end{array}$ & $\begin{array}{c}\text { Group II (Control) } \\
\mathrm{n}=20\end{array}$ & $\begin{array}{c}\text { Level of significance } \\
\text { (p-Value) }\end{array}$ \\
\hline Apo A1 (mg/dl) & $\begin{array}{c}91.84 \pm 11.2 \\
(68.0-105.0)^{*}\end{array}$ & $\begin{array}{c}123.2 \pm 10.5 \\
(105.0-145.0)^{*}\end{array}$ & 0.001 \\
Apo B $(\mathrm{mg} / \mathrm{dl})$ & $135.3 \pm 23.0$ & $66.2 \pm 10.0$ & 0.001 \\
& $(106.0-187.0)^{*}$ & $(55.0-94.9)^{*}$ & \\
\hline
\end{tabular}

$\mathrm{P}$ value reached by unpaired t test $\quad *$ Paranthesis shows range

\section{Table III}

Comparison of the ratio of Apo B / Apo Al between study subject.

Parameter Group I (cases) Group II $\quad$ Level of significance

(p-Value)

\begin{tabular}{llll}
\hline Apo B / Apo A1 & $1.48 \pm .03$ & $0.54 \pm 0.1$ & 0.001 \\
\hline
\end{tabular}

$\mathrm{P}$ value reached by unpaired t test 


\section{Discussion}

In this study MI patients found to have serum apoB concentration significantly increased and apoA1 concentration significantly decreased in comparison to control. A similar phenomenon was reported in many other studies around the world. ${ }^{18,19,20,21,1,22,23,24,25}$.

Atherogenic lipoproteins particles are heterogenous with respect to their cholesterol content but homogenous with respect to their apoB content. So serum apoB more accurately reflects the total number of circulating atherogenic particles which their total cholesterol content cannot. For example small dense LDL particles are cholesterol depleted compared to large LDL particles but all LDL subtypes contain one molecule apoB .So the number of circulating LDL particle is more accurately measured by their apo-B content rather then LDL-C. Although about $70 \%$ of plasma cholesterol is carried by LDL but apart from LDL, there are number of other highly atherogenic circulating lipoproteins, all of which contain apo-B. Therefore serum apoB is the more comprehensive and reliable marker of atherogenicity rather than the LDL-C alone ${ }^{26,27,28}$.

HDL is regarded as an anti-atherogenic lipoprotein. Various subtypes of HDL (e.g. HDL1, HDL2, HDL3 etc.) has been described which differ from each other with respect to their apoprotein and antiatherogenicity. To be a antiatherogenic, HDL needs to contain apo-A1 which is not true for all HDL subtypes (e.g. $\mathrm{HDL}_{1}$ contain no apo A1) ${ }^{10}$. Therefore it mightbe possible for an individual to present with MI having normal HDL-C but decreased serum apoA1 concentration due to predominance of HDL1 subtype or the HDL subtypes without apoA1.

\section{Conclusion:}

It can be concluded from this study that; serum ApoA1 and ApoB are more reliable tool to assess and evaluate the atherosclerotic disorders specially the CAD. Therefore if accurate precise and affordable standardized methods be come available for the measurement of apoA1 and apoB, these apoproteins measurement may be recommended as a routine laboratory test to evaluate the MI patient \& to assess the risk of MI.

\section{Reference}

1. Genest j, Mcnamara JR, Ordovas JM, Jenner JL, Silberman SR,Anderson KM and Wilson PWF; Lipoproteins cholesterol, Apolipoprotein A1 and B and lipoprotein (a) abnormalities in men with premature coronary artery disease; J Am Coll Cardiol; 1992;19:792-802.

2. Ginsberg H N \& Goldberg I J ; Disorder of intermediary metabolism; in: Harrisons principles of internal medicine; Braunwald E, Fauci A.S. \& Kasper D.L.; (eds)13th edition: McGraw Hill publishers; USA,2001; pp1377-1387.

3. Durrington PN, Hunt L, Ishola M \& kane J; Serum apolipoproteins A1 and B lipoproteins in middle age men with and without previous myocardial infarction; Br Heart J;1986; 56: 206-212.

4. Stein EA and Myer GL; Lipid, lipoprotein and apolipoproteins; in : Teitz fundamentals of clinical chemistry; ed.Burtis CA and Ashwood ER (eds); 4th edition; Philadelphia WB saundex company; 1996;375.

5. Sveger T \& Fex G; Apolipoprotein A1 and B levels in adolescents: A trial to define subjects at risk for coronary heart disease; Acta paediatr Scand; 1983: 72: 499-504.

6. Kwiterovich PO \& Sniderman AD; Atherosclerosis and apoprotein Band A1; Prev Med, 1983; 12: 815-834.

7. She MP,Liang P, huang YD, Cai CB, Ran BF, Wang ZL and Xia RY; HDL and apolipoproteinA(apoA1):Their effects on retardation of lipid deposition in aortic intima;Clin med J.(Engl);1992 May;105(5):369-373.

8. Franzen J \& Fex G; Low serum apolipoprotein A1 in acute myocardial infarction survivors with normal HDL cholesterol; Atherosclerosis: 1986;59:37-42.

9. Stewart GM; The meaning of a new marker for coronary artery disease; N Engl J Med; 1983;309(7):426-427.

10. Stein EA and Myer GL; Lipid, lipoprotein and apolipoproteins: in: Tietz fundamentals of Clinical Chemistry; ed.Burtis CA and Ashwood ER (eds); 4th edition; Philadelphia WB saundex company; 1996;pp375.

11. Grundy SC, Vega GL, Kesaniemi YA; Abnormalities in metabolism of low density lipoproteins associated with coronary heart disease; Acta Med Scand (suppl) 1985; 701: 23-37.

12. Hoff HF, Heiderman CL, Gaubatz JW \& Titus JL; Quatitation of apoB in human aortic fatty streaks: A comparison with grossly normal intima and fibrous plaques; Atherosclerosis ; 1978; 30:263-268.

13. Sniderman AD \& Cianflone K; Measurement of Apoproteins: Time to improve the diagnosis and treatment of the Atherogenic dyslipoproteinemias; Clin Chem ; 1996;42(4): 489-491.

14. Gardner CD ,Fortmann SP, krauss RM; ApoB/ApoA1 ratio is more robust an specific marker; JAMA 1996; 276: 875881 . 
15. Dati F,Tate J; ejiFcc vol-13 no3:http//www.If cc.org/ejifcc/vol 13 no3/130301003.htm.

16. Lopes- virella MF L, Virella G and Evans G; Immunonephelometric Assay of Human apolipoprotein A1;Clin Chem; 1980;26(8):1205-1208.

17. Heuck CC \& Schlier G; Nephelometer of Apolipoprotein B in Human Serum ;Clin Chem 1979; 25(1):221-226.

18. Avogaro,Bon GB, Cazzolato G and Roral E; Relationship between apolipoproteins and chemical componants of lipoproteins in survivors of myocardial infarction; Atherosclerosis ; 1980;37:69-76.

19. BackerG, Hulstaert F, Munck k, Rosseneu M, Vanparijs L and Dramaix M; Serum lipids and apoproteins in a student whose parents suffered prematurely of myocardial infarction; Am Heart J; 1986; 112: 478-484.

20. Freedman DS ,Srinivasan SR, Shear CL, Franklin FA, Webber LS and Berenson GS; The relation of apolipoprotein A1 and B in children to parental myocardial infarction;N Engl J Med; 1986; 315;721-726.

21. Vanstiphout WA HJ, Hofman A, Kruijssen HACM, \& Vermeeren $\mathrm{R}$; is the ratio of $\mathrm{ApoB} / \mathrm{apoA} 1$ an early predictor of coronary Atherosclerosis? Atherosclerosis 1986;62: 179182.
22. Kukita H ,Hamada M, Hiwada K\& Kokubu T; Clinical significance of measurements of serum apolipoprotein $\mathrm{A} 1$,All and B in hyper triglyceridemic male patients with without coronary artery disease; Atherosclerosis; 1985 ; 55: 143-149.

23. Al-Muhtaseb N, Hayet N \& Al-Khafaji M; Lipoproteins and apolipoprotein in young male servivors of myocardial infraction; atherosclerosis; 1989;77 (2-3):131-138.

24. Durrington PN, Hunt L, Ishola $M$ \& Arrol S ;Apolipoproteins(a,)A1 and B and parental history in men with early onset ischemic heart disease; The Lancet;1988;14: 1070-1073.

25. Zunic G, Jelic- lvanovic Z, Spasic S, Stojiljkovic A and Singh NM ; Reference values for apolipoproteins A1and B healthy subjects by Age; clin chem.; 1992;38(4): 566-569.

26. Miremadis S, Sinderman A,\& Frohlich J; Clinical chemistry, 2002;48(3)484-488.

27. Berneis KK,Krauss RM, Metabolic origens and clinical significance of LDL hheterogenecity; J lipid Resechers, 2002; 43: 1363-79.

28. Sinderman AD, Furberg CD, Keech A etal;Lancet, 2003,361,777-780 